\title{
Saskatchewan's Only Trumpeters
}

by Fred G. Bard and Fred W. Lahrman, S.M.N.H.

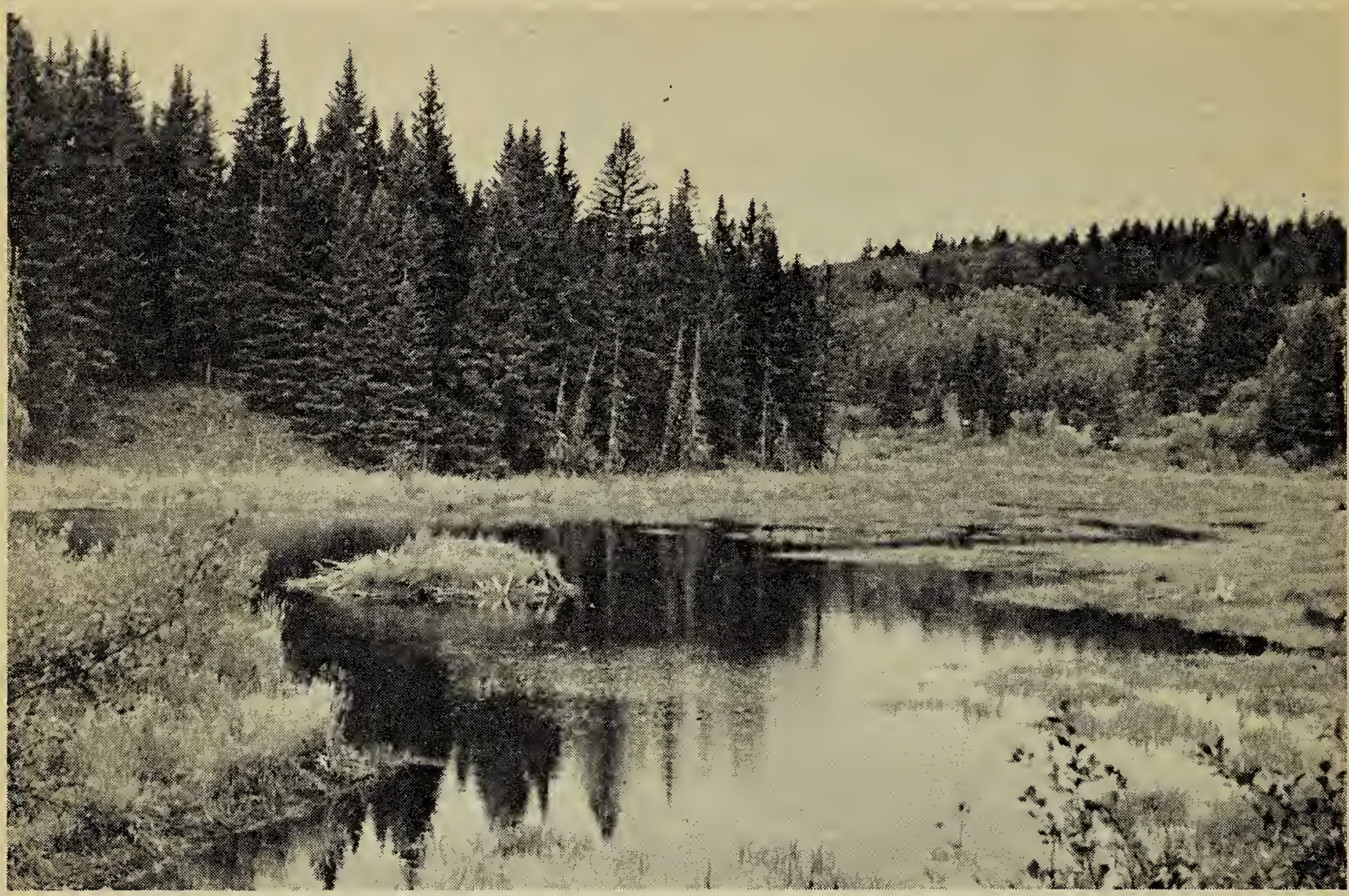

One of Saskatchewan's two pairs of Trumpeter Swans nested this summer on this beaver pond on Belanger Creek. Note how the swans depend upon the beaver-since there is no food in lakes like Cypress Lake, the beaver pond provides a more suitable nesting site. A second pair of Trumpeters with three young was seen by Joyce Dew in J11y, 1961, at Adams Lake.

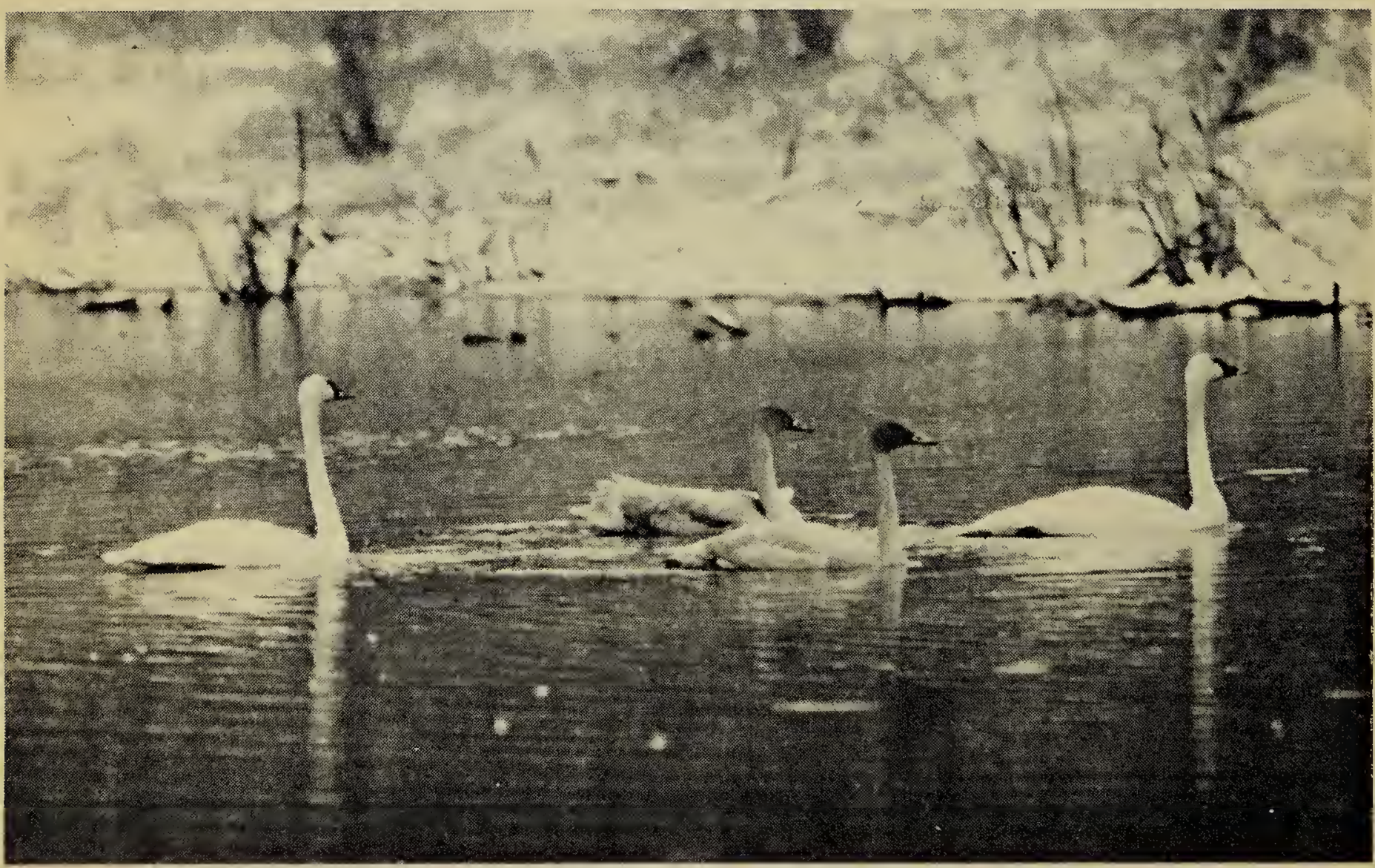

Winter's first snow catches the Trumperters still on summer territory. The adult pair is shown here (October 17, 1961) with two remaining young, one young having already disappeared. The young bird to the left of the photo has a broken leg. 


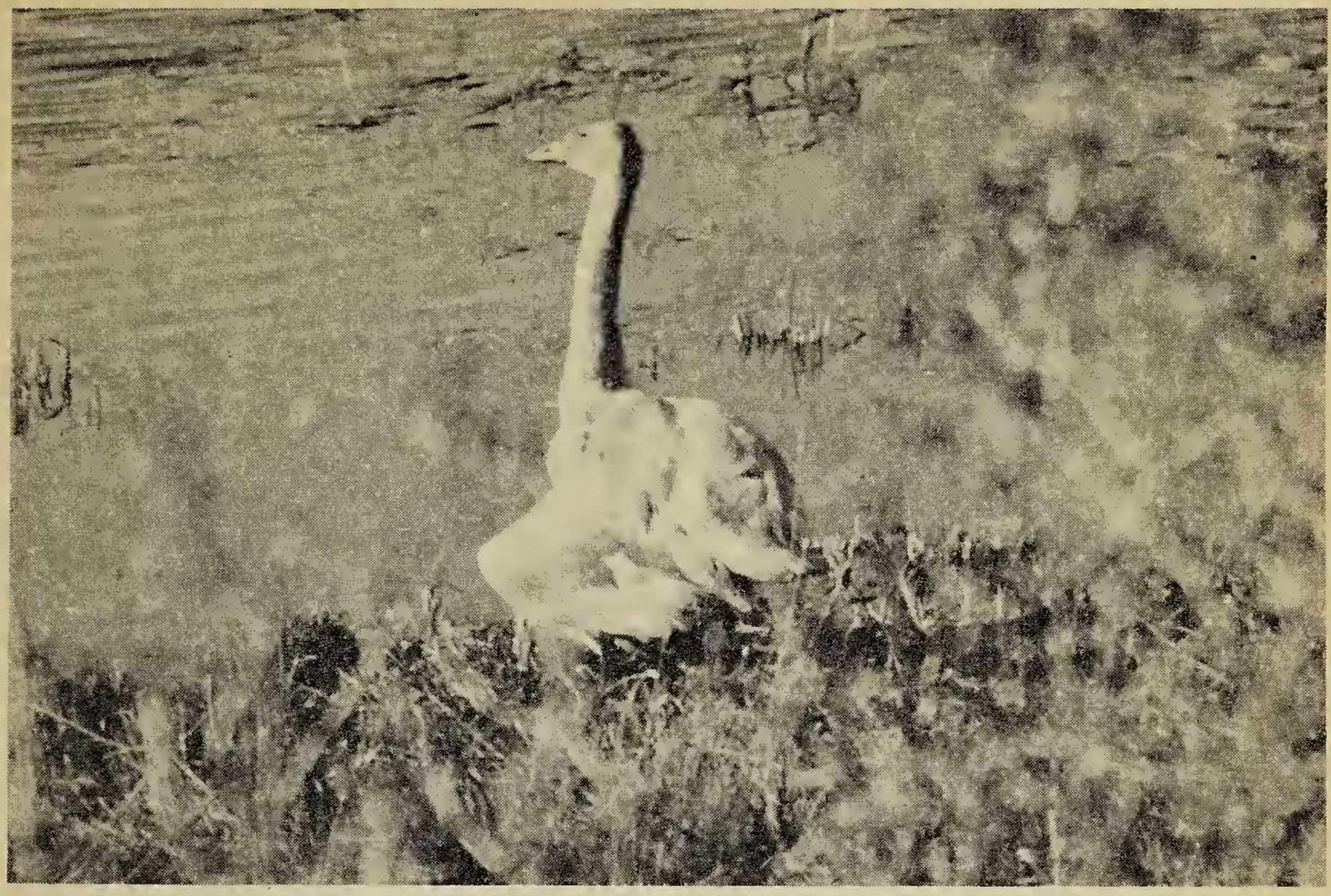

To give the young flying experience, the swans usually leave the home pond for several days. These flights may take them over hunting areas, and it is therefore very difficult to provide probection once the birds leave the nesting pond. This is the young swan found injured this fall.

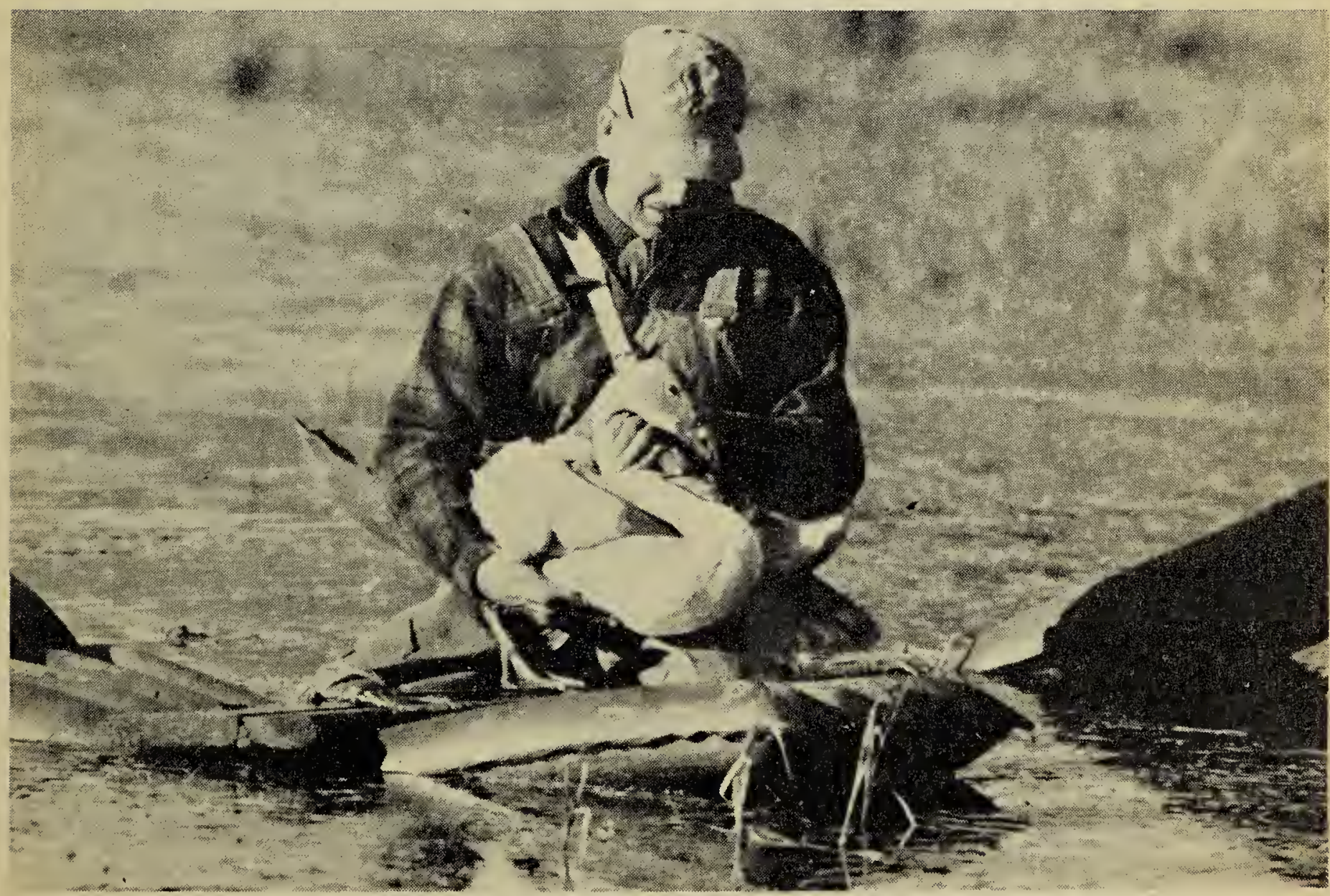

With a raft improvised of air mattresses, the wounded Trumpeter is rescued to be sent to Tom Baines, Curator of the Calgary Zoo, for the winter. A resident of the area, Ken Bowles, tells us that in 1960 no young mignated, having disappeared one by one when full grown. To save these rare Trumpeters, we urge you NEVER TO SHOOT WHITE BIRDS. 